xác định các triệu chứng lâm sàng, cận lâm sàng đóng vai trò quan trọng giúp chẩn đoán đúng, điều trị kịp thời cũng như hạn chế các biến chứng.

\section{TÀI LIÊU THAM KHẢO}

1. WHO Cannabis. WHO. https:// www.who.int/substance_abuse/facts/cannabis/en/. Accessed May 5, 2020.

2. Sharma $P$, Murthy $P$, Bharath MMS. Chemistry, Metabolism, and Toxicology of Cannabis: Clinical Implications. Iran J Psychiatry. 2012;7(4):149-156.
3. Tournebize J, Gibaja V, Kahn JP. Acute effects of synthetic cannabinoids: Update 2015. Subst Abuse. 2017;38(3):344-366. doi:10.1080/ 08897077.2016.1219438

4. Noble MJ, Hedberg K, Hendrickson RG. Acute cannabis toxicity. Clin Toxicol. 2019;57(8):735742. doi:10.1080/15563650.2018.1548708

5. Hoyte CO, Jacob J, Monte AA, Al-Jumaan $M$ Bronstein AC, Heard $\mathrm{KJ}$. A characterization of synthetic cannabinoid exposures reported to the National Poison Data System in 2010. Ann Emerg Med. 2012;60(4):435-438. doi:10.1016/ j.annemergmed.2012.03.007.

\title{
NGHIÊN CỨU BÀO CHẾ VIÊN NANG LỤC VỊ ĐİA HOÀNG
}

\author{
Nguyễn Văn Hưng ${ }^{1}$, Lê Thị Minh Nguyệt ${ }^{1}$, Lê Thị Khánh Ly ${ }^{1}$, \\ Đỗ Nguyễn Hạnh Phước ${ }^{1}$, Lê Nguyễn Bảo Thi ${ }^{1}$, Trần Văn Trọng ${ }^{1}$, \\ Nguyễn Thế Dũng ${ }^{1}$, Phạm Hoàng Đức ${ }^{1}$
}

\section{TÓM TẮT}

Mục tiêu: Xây dựng qui trình bào chế viên nang Lục vị địa hoàng và đánh giá chất lượng sản phẩm bào chế. Đối tướng và phương pháp nghiên cứu: Bài thuốc Lục vị địa hoàng; phương pháp: khảo sát thời gian sắc đế bào chế cao, khảo sát tỷ lệ tá dược để bào chế viên nang Lục vị địa hoàng và đánh giá chất lương sản phẩm. Kểt quả: Cao Luc vi đia hoàng được điêu chế bằng phương pháp sắc trong thời gian 60 phút. Viên nang Lục vị đia hoàng chứa $150 \mathrm{mg}$ cao phối hợp với Lactose, Tinh bột, Magnesi stearate, Aerosil và đat các qui chuẩn chẩt lương qui định. Kết luận: Đã nghiên cứu bào chế được viên nang Lục vị hoàn làm cơ sở cho việc nghiên cứu sâu hớn nhằm phát huy các giá trị của bài thuốc Y học cổ truyền.

Từ khóa: "Lục vị địa hoàng", viên nang, độ rã, độ ẩm.

\section{SUMMARY}

\section{STUDY ON PREPARATION OF "LUC VI DIA} HOANG" CAPSULES

Objectives: To develop a process for preparing Luc vi dia hoang capsule and evaluate the quality of prepared products. Subjects and Methods: "Luc vi dia hoang" remedy, surveying the high preparation time, surveying the proportion of excipients for preparing Luc vi dia hoang capsules and evaluating product quality. Results: Luc vi dia hoang condensed status was prepared by the decoction method in 60 minutes. Luc vi dia hoang capsule contains $150 \mathrm{mg}$ active substance combined with Lactose, Starch, Magnesi stearate, Aerosil and meets the specified quality standards. Conclusion: Research has been made to prepare the capsule of Luc vi dia hoang as

${ }^{1}$ Trường Đại hoc Y - Dượ, Đai hoc Huế Chịu trách nhiệm chính: Nguyễn Văn Hưng Email: nvhung.yhct@huemed-univ.edu.vn Ngày nhân bài: 11.8 .2021

Ngày phản biên khoa hoc: 11.10.2021

Ngày duyệt bài: 18.10 .2021 the basis for further research in order to promote the values of traditional medicine.

Keywords: "Luc vi dia hoang", capsules, disintegration, moist.

\section{I. ĐĂT VẤN ĐỀ}

Theo Y học cổ truyền (YHCT) nguồn gốc bênh tật phát sinh là do mất cân bằng âm dương [7]. Vì vậy nguyên lý điều trị theo YHCT là lập lại cân bằng âm dương trong cơ thể, nâng cao sức khoẻ. Thuốc YHCT cũng được sử dụng dựa trên mục đích điều hoà cân bằng âm dương. Việc bào chế và sử dụng thuốc YHCT đa dạng, phong phú; thông qua việc bào chế có thể làm tăng tác dụng điều trị của các vị thuốc và bài thuốc. Bài thuốc "Lục vị địa hoàng" là bài thuốc cổ phương của Đại danh Y Trương Trọng Cảnh có tác dụng điều chỉnh, tư bổ phần âm của cơ thể [3], [5], [6]. Ở Việt Nam đại danh y Hải Thượng Lãn Ông cũng đã ứng dung bài thuốc Lục vi đia hoàng làm nền tảng cắn bản để điều trị nhiều bệnh lý khác nhau. Hiện nay, bài thuốc Lục vị địa hoàng được ứng dụng rộng rãi trên lâm sàng và được sử dụng dưới nhiều dạng khác nhau như thuốc sắc, thuốc hoàn [4]. Các dạng bào chế khác nhau của các bài thuốc $Y$ học cổ truyền sẽ làm đa dạng, phong phú các chế phẩm trên thị trường đáp ứng nhu cầu chăm sóc sức khoẻ của nhân dân. Để góp phần phát huy các giá trị của bài thuốc, việc áp dụng các dang bào chế thích hợp để thuận tiện cho người sử dụng nhằm nâng cao hiệu quả điều trị là vấn đề cần được quan tâm [1], [2]. Viên nang là dạng bào chế có nhiều ưu điểm như gọn, nhỏ, dễ sử dụng, có sinh khả dụng cao, che dấu được mùi vị khó chịu của dược liệu.... Trên cơ sở đó, chúng tôi tiến hành 
đề tài "Nghiên cứu bào chế viên nang lục vị địa hoàng" với hai mục tiêu:

1. Xây dựng quy trinh bào chế viên nang Lục vi đia hoàng.

2. Đánh giá chât lượng sản phẩm đã bào chế. II. ĐỐI TƯợNG VÀ PHƯƠNG PHÁP NGHIÊN CỨU

2.1. Đối tượng

- Bài thuốc Lục vị địa hoàng (tính trên 1 thang).

- Tá dược: Tinh bột, Lactose, Magnesi stearate, Talc, Aerosil......

- Thiết bị nghiên cứu: Máy sắc thuốc, cân phân tích, tủ sây, rây, khuôn đóng nang...

\subsection{Phương pháp nghiên cứu}

Phương pháp xây dựng quy trình bào chế. Bài thuốc Lục vị địa hoàng được tiến hành điều chế cao bằng phương pháp sắc [1]. Khảo sát thời gian sắc thích hợp để bào chế cao Lục vị địa hoàng, khảo sát các tỷ lệ tá dược (tá dược độn, tá dược rã, tá dược trơn...) thường được sử dụng để tạo cốm, định hướng hàm lượng và thành phần công thức để xây dựng qui trình bào chế viên nang Lục vị địa hoàng.

Phương pháp đánh giá một số chỉ tiêu của cốm Lục vị địa hoàng

- Lưu tính: được đánh giá bằng cách xác định góc nghỉ hình thành từ đường sinh và đường kính đáy của khối cốm tạo thành trong điều kiện quy đinh.

- Độ ẩm: dựa vào khối lượng mất đi sau khi sấy để tính độ ẩm của khối cốm.

Phương pháp đánh giá chất lượng sản phẩm bào chế

- Đánh giá một số tiêu chuẩn chất lượng cho sản phẩm dựa trên Dược điển Việt Nam IV và một số tài liệu.

\section{KẾT QUẢ NGHIÊN CỨU}

3.1. Nghiên cứu xây dựng quy trình bào chế viên nang Lục vị địa hoàng

Khảo sát thời gian bào chế cao Luc vị địa hoàng. Bài thuốc Lục vị địa hoàng có tổng khối lượng là $100 \mathrm{~g}$ được tiến hành sắc với nước cất, sau đó cô đến thể chất cao đặc. Dựa vào khối lượng cao để lựa chọn thời gian sắc thích hợp.

hoàng

Bảng 1. Thời gian bào chế cao Luc vị địa

\begin{tabular}{|c|c|c|c|}
$\begin{array}{c}\text { Thời gian } \\
\text { Khồi lướng } \\
\text { cao }(\mathbf{g})\end{array}$ & $\mathbf{4 5}$ phút & $\mathbf{6 0}$ phút & $\mathbf{9 0}$ phút \\
\hline Lần 1 & $0,75 \mathrm{~g}$ & $0,92 \mathrm{~g}$ & $0,90 \mathrm{~g}$ \\
\hline Lần 2 & $0,81 \mathrm{~g}$ & $0,89 \mathrm{~g}$ & $0,93 \mathrm{~g}$ \\
\hline Lân $\mathbf{3}$ & $0,79 \mathrm{~g}$ & $0,90 \mathrm{~g}$ & $0,91 \mathrm{~g}$ \\
\hline Trung bình & $\mathbf{0 , 7 8 g}$ & $\mathbf{0 , 9 0 g}$ & $\mathbf{0 , 9 1 g}$ \\
\hline
\end{tabular}

Nhân xét: Khi tăng thời gian sắc thì lượng cao chiết được tăng lên, tuy nhiên khi tăng từ 60 phút lên 90 phút thì lượng cao tăng thêm không đáng kể. Do đó ta chon thời gian sắc là 60 phút.

\subsection{Khảo sát tỷ lệ các tá dược}

Khảo sát các tá dược độn

Bảng 2. Các công thức khảo sát tá dược độn

\begin{tabular}{|c|c|c|c|}
\hline Thành phân & CT1 & CT2 & CT3 \\
\hline $\begin{array}{c}\text { Cao Lục vị địa } \\
\text { hoàng }\end{array}$ & \multicolumn{3}{|c|}{$150 \mathrm{mg}$} \\
\hline Tinh bột & $300 \mathrm{mg}$ & $275 \mathrm{mg}$ & $250 \mathrm{mg}$ \\
\hline Lactose & $100 \mathrm{mg}$ & $125 \mathrm{mg}$ & $150 \mathrm{mg}$ \\
\hline Khối lượng & & $550 \mathrm{mg}$ & \\
\hline $\begin{array}{c}\text { Nhận xét cảm } \\
\text { quan }\end{array}$ & $\begin{array}{c}\text { Bô̂t khô, } \\
\text { khó xát } \\
\text { hât, hât } \\
\text { khống đều }\end{array}$ & $\begin{array}{c}\text { Đợa phải, } \\
\text { dễ xát } \\
\text { hạt, hạt } \\
\text { đều }\end{array}$ & $\begin{array}{c}\text { Bô̂t hơi } \\
\text { nhắo, khó } \\
\text { xát hạt }\end{array}$ \\
\hline
\end{tabular}

Nhận xét: Khi thay đổi tỷ lệ hai loại tá dược Tinh bột và Lactose thì thể chất của khối bột tạo thành thay đổi. Với CT2, khối bột tạo thành có độ vừa phải nên dễ xát hạt và hình thức hạt đẹp, tương đối đồng đều nên ta chọn phối hợp $275 \mathrm{mg}$ Tinh bột và $127 \mathrm{mg}$ Lactose với $150 \mathrm{mg}$ cao Lục vị địa hoàng để làm cốm.

Khảo sát các tá dược trơn

Khảo sát các tá dược trơn dùng đơn lẻ

Bảng 3. Các công thức khảo sát tá dược trơn dùng đơn lẻ

\begin{tabular}{|c|c|c|c|}
\hline Thành phần & CT4 & CT5 & CT6 \\
\hline Cốm Lục vị địa hoàng & \multicolumn{3}{|c|}{$550 \mathrm{mg}$} \\
\hline Magnesi stearate & $3 \%$ & & \\
\hline Talc & & $5 \%$ & \\
\hline Aerosil & & & $0,4 \%$ \\
\hline Lưu tính - góc a $(\mathrm{n}=3)$ & $38^{0}$ & $42^{0}$ & $31^{0}$ \\
\hline Độ ẫm $(\mathrm{n}=3)$ & $7,32 \%$ & $5,49 \%$ & $6,25 \%$ \\
\hline
\end{tabular}

Nhận xét: Khi phối hợp cốm với các tá dược trơn Magnesi stearate, Talc, Aerosil thì cả ba công thức trên đều đạt yêu cầu về độ ẩm (< $9 \%$ ) và không đạt góc $\mathrm{a}<30^{\circ}$ nên không thể đóng nang. Do đó nghiên cứu tiến hành phối hợp hai loại tá dược trơn nhằm điều hòa sự chảy của cốm.

Phối hợp các loại tá dược trơn

Bảng 4. Các công thức khi phôi hợp các tá dược trơn

\begin{tabular}{|c|c|c|c|c|}
\hline Thành phân & CT7 & CT8 & CT9 & CT10 \\
\hline Cốm Lục vị địa hoàng & \multicolumn{5}{|c|}{$550 \mathrm{mg}$} \\
\hline Magnesi stearate & $2 \%$ & $2 \%$ & $1 \%$ & $1 \%$ \\
\hline Talc & $3 \%$ & & $5 \%$ & \\
\hline Aerosil & & $0,1 \%$ & & $0,3 \%$ \\
\hline Lưu tính-góc a(n=3) & $37^{0}$ & $28^{0}$ & 440 & $36^{0}$ \\
\hline Độ ấm (n=3) & $6,12 \%$ & $5,82 \% 5,95 \%$ & $6,43 \%$ \\
\hline
\end{tabular}


Nhận xét: Khi phối hợp hai loại tá dược trơn có tính năng khác nhau thì lưu tính của bột được cải thiện trong đó CT8 có góc $a<30^{\circ}$ đạt yều cầu để đóng nang.

Như vậy công thức cho 1 viên nang Lục vị địa hoàng là: Cao Lục vị địa hoàng: 150 mg; Tinh bột: 275mg; Lactose: 125mg; Magnesi stearate: 2\%; Aerosil: 0,1\%

Xây dựng quy trình bào chế viên nang Lục vị địa hoàng

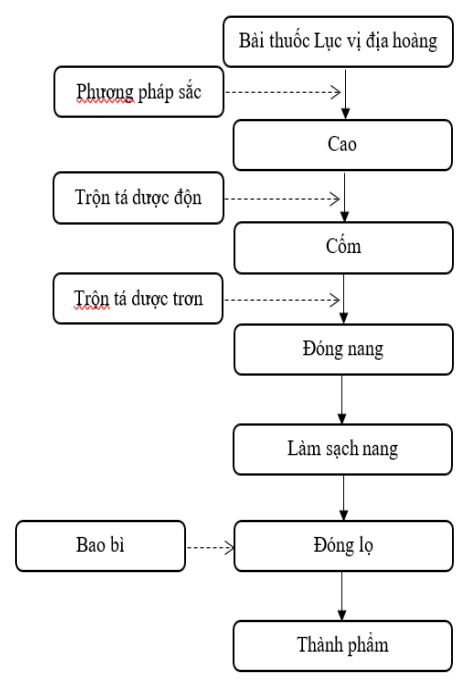

Sơ đồ 1. Quy trình bào chế viên nang Luc vị địa hoàng

Viên nang Lục vị địa hoàng được bào chế theo phương pháp đóng nang thủ công. Quy trình bào chế này đơn giản, dễ thực hiện.

Đánh giá chất lượng sản phẩm bào chế

Dựa trên tiêu chuẩn kiểm nghiệm thuốc viên nang theo Dược điển Viêt Nam IV và một số tài liệu tiến hành đánh giá chất lượng sản phẩm bào chế.

- Hình thức: viên nang trong, nhăn, sạch, chứa cốm bên trong màu đen.

- Độ rã: trung bình 12 phút (< 30 phút): Đạt.

- Độ đồng đều khối lượng: 562,41mg (trung bình khối bột trong nang $\mathrm{m} \pm$ 7,5\%): Đạt.

\section{BÀN LUẬN}

Bài thuốc Lục vị địa hoàng thường được sử dụng khá phổ biến đế điều trị nhiều trường hợp bểnh lý khác nhau, do đó đề tài tiến hành nghiên cứu bào chế nó ở dưới dạng viên nang nhằm thuận tiện cho người sử dụng. Từ những nguyên liệu ban đầu, tiến hành sắc trong 60 phút để được cao Lục vị địa hoàng. Qua khảo sát nhận thẩy nếu sắc ở thời gian ít hơn 60 phút thì lượng cao giảm đi nhiều chứng tỏ chưa chiết kiệt hết các hoạt chất có trong dược liệu. Nếu tiến hành sắc trong thời gian lâu hơn 60 phút thì lượng cao tăng lên không đáng kể nhưng lại tốn nhiều thời gian và nhiên liệu, nên tốt nhất là sắc trong 60 phút.

Khi phối hợp cao Lục vị địa hoàng với các tỷ lệ Tinh bột và Lactose khác nhau thì khối ẩm tạo thành có các đặc điểm khác nhau. Qua khảo sát, CT2 với $275 \mathrm{mg}$ Tinh bột và $125 \mathrm{mg}$ Lactose thì khối bột có độ ẩm vừa phải dễ dàng xát hạt và hạt cốm tạo thành tương đối đều, thuận tiện cho việc đóng nang.

Để đảm bảo các tiêu chí khác khi đóng nang, tiến hành khảo sát để lựa chọn tá dược trơn giúp cốm trơn chảy tốt vào nang và đạt độ đồng đều về khối lượng cốm trong nang. Khi sử dụng riêng lẻ các tá dược trơn thì các giá trị góc a cho thấy không có loại tá dược nào phù hợp. Khi phối hợp các loại tá dược trơn có đặc tính khác nhau, do Magnesi stearate có tác dụng giảm ma sát, chống dính trong khi Talc, Aerosil lại giúp điều hòa sự chảy nên đề tài tiến hành phối hợp hai nhóm tá dược này: Magnesi stearate + Talc, Magnesi stearate + Aerosil. Kết quả cho thấy sự phối hợp Magnesi stearate + Aerosil cải thiện đáng kể lưu tính của khối cốm. Do đó nghiển cứu đã chọn tỷ lệ này để xây dựng công thức và qui trình bào chế viên nang Lục vị địa hoàng.

Qui trình bào chế viên nang với các bước đơn giản, dễ thực hiện. Sản phẩm bào chế xong được tiến hành đánh giá các tiêu chí như cảm quan, độ rã, độ đồng đều khối lượng và đạt yêu cầu.

\section{KẾT LUÂ̂N}

Bài thuốc Lục vị địa hoàng được chiết bằng phương pháp sắc trong thời gian 60 phút sẽ thu được khối lượng cao tối ưu nhất. Viên nang Lục vị địa hoàng được bào chế theo phương pháp đóng nang thủ công với khối lượng trung bình $562,41 \mathrm{mg} / \mathrm{nang}$, trong đó hàm lượng cao chiếm $150 \mathrm{mg}$. Viên nang Lục vị địa hoàng có hình thức đẹp, đạt các tiêu chuẩn đề ra và thuận lợi cho việc sử dụng.

Đề tài là cơ sở khoa học cho các nghiên cứu sâu hơn tiếp theo nhằm đa dạng hóa các sản phẩm có nguồn gốc từ dược liệu trên thị trường, góp phần phát huy giá trị của các bài thuốc Y học cổ truyền của dân tộc ta.

\section{TÀI LIỆU THAM KHẢO}

1. Bào chế Đông Dược: Nguyễn Nhược Kim, Trần Thuý, Lê Thị Hồng Hoa, Hoàng Minh Chung, Nguyễn Thị Minh Tâm, Trần Lưu Vân Hiền, Nhà xuất bản Y học, Hà Nội 2005, tr.23 - 24.

2. Hoàng Minh Châu, Nguyễn Nhật Thành, Nghiên cứu chuyển dạng bào chế bài thuốc Lục vị, Tạp chí Y học Thành phố Hồ Chí Minh, 2002, tr.27-32.

3. Hai trăm năm mươi bài thuốc Đông y cổ truyền chọn lọc, Nhà xuất bản Thanh niên, 
Thành phố Hồ Chí Minh, 2008, tr.237 - 239.

4. Kỹ thuật bào chế và chế biến thuốc cổ truyên: Phùng Hoà Bình, Phạm Xuân Sinh. Võ Xuân Minh, Vũ Văn Điền, Nhà xuất bản Y học, Hà Nội, 2004, tr.7 - 10, 69 - 70, 83 - 103.
5. Phương tễ họ: Hoàng Duy Tân, Nhà xuất bản Thuâan Hoá, 200̄9, tr.642 - 647.

6. Phương thuốc cố truyên: Hoàng Bảo Châu, Nhà xuất bản Y học, Hà Nội, 1998, tr.173 - 174.

7. Y lý Y hoc cố truyền: Nguyễn Thi Tân, Nhà xuất bản Đại học Huế, 2015, tr.13 - 28.

\section{KIẾN THỨC VÀ THƯC HÀNH CHĂM SÓC TRƯỚC SINH CỦA CÁC THAI PHU CÓ TUỔI THAI TỪ ĐỦ 37 TUẦ TRỞ LÊN TẠI TRUNG TẨM Y TẾ HUYÊ̂N XUÂN LộC, ĐỒNG NAI}

\section{TÓM TẮT}

Đăt vấn đề: Chăm sóc trước sinh là những chăm sóc mà thai phụ nhận được nhằm đảm bảo những điều kiện tốt nhất về sức khỏe cho cả me và thai trong suốt thai kỳ. Chăm sóc trước sinh có vai trò quan trọng trong việc giảm tỷ lệ tử vong me và tử vong sơ sinh trên thế giới, đặc biệt là ở các quốc gia đang phát triển. Nghiên cứu được tiến hành nhằm khảo sát thực trạng kiến thức và thực hành chăm sóc trước sinh cửa các thai phụ tại Huyện Xuân Lộc, Đồng Nai. Hiện vẫn chưa có nghiên cứu về vấn đề chăm sóc trước sinh tại địa phương. Mục tiêu: Xác định tỷ lệ thai phụ đi khám thai tối thiểu 4 lần và tỷ lể thai phụ có kiến thức tốt, hành vi đúng về chăm sóc trước sinh tại Trung tâm $Y$ tế Huyện Xuân Lộc. Phương pháp nghiên cứu: Thiết kế nghiên cứu cắt ngang được thực hiện từ 11/2020 đến 05/2021 trên 332 thai phụ có tuổi thai từ đủ 37 tuần trở lên đến khám tại TTY̛T Huyện Xuân Lộc, với điểm cắt $75 \%$ được sử dụng để xác định mức độ kiến thức tốt hoặc thực hành đúng về chăm sóc trước sinh của các thai phụ. Kết quả: Tỷ lệ thai phụ đi khám thai tối thiểu 4 lân trong thai kỳ là $86,4 \%$. Tỷ lệ thai phụ có kiến thức tốt về chăm sóc trước sinh là $89,5 \%$. Tỷ lệ thai phụ có thực hành đúng về chăm sóc trước sinh là 87,6\%. Kết luận: Tỷ lệ thai phụ đi khám thai tối thiểu 4 lần trong thai kỳ cững như tỷ lệ thai phụ có kiến thức tốt, hành vi đúng về chăm sóc trước sinh đều cao hơn tỷ lệ chung của cả nước. Tuy nhiên, kiến thức của thai phụ về các vấn đề dinh dướng, lao động và nghỉ ngơi trong thai kỳ vẫn chưa thực sự tốt. Cẩn tiếp tục tăng cường các biện pháp giáo dục, truyền thông và tư vấn để cải thiên các khía canh còn hạn chế của chương trình chăm sóc trước sinh tại địa phương.

Tư khóa: kiến thức, thực hành, chăm sóc trước sinh, thai phụ.

\section{SUMMARY \\ KNOWLEDGE AND PRACTICE REGARDING}

\footnotetext{
${ }^{1}$ Trung tâm Y tế Huyện Xuân Lộc, Đồng Nai

2Đai hoc Y Dướ TPHCM

Chịu trách nhiệm chính: Trần Lệ Thủy

Email: tranlethuy@ump.edu.vn

Ngày nhận bài: 9.8.2021

Ngày phản biên khoa hoc: 8.10.2021

Ngày duyệt bài: 15.10 .2021
}

Trần Đình Chắt ${ }^{1}$, Trần Lệ Thủy ${ }^{2}$

\section{ANTENATAL CARE AMONG PREGNANT WOMEN AT OR BEYOND 37 0/7 WEEKS OF GESTATION IN XUAN LOC HEALTH CENTER, DONG NAI PROVINCE}

Background: Antenatal care (ANC) is the care a women receives throughout pregnancy in order to ensure that both the mother and her child remain healthy. ANC plays an important role in reducing maternal and neonatal morbidity and mortality, especially in developing countries. This study aims to assess the conditions of knowledge and practice toward ANC among pregnant women in Xuan LoC District, Dong Nai Province. There are currently no studies on prenatal care in this area. Objectives: Determine the proportion of pregnant women receiving at least four (ANC4+) visits. We also determine the proportion of pregnant women having good knowledge and correct practice regarding ANC at Xuan Loc Health Center. Methods: A cross-sectional study was conducted on 332 pregnant women, who have gestational age at or beyond $370 / 7$ weeks and checking-up ANC at Xuan Loc Health Center from November 2020 to May 2021. Beside assessing the frequency of ANC visits, we also use the cut-off point at $75^{\text {th }}$ percentage to determine the level of knowledge and practice regarding ANC of these womens. Results: The percentage of pregnant women having at least four or more ANC visits is $86.4 \%$. Among 332 pregnant women, we found that $89.5 \%$ have good knowledge while $87.6 \%$ of them were noted to have correct practice about ANC. Conclusion: Our research's results about the proportion of pregnant women either receiving ANC4+ visits or having good knowledge and correct practice toward ANC are higher than the total proportion of country. However, the level of knowledge of pregnant women regarded the importance of nutrition and how they work or sleep during pregnancy were poor. These findings can be used to plan a social media and education campaign-based customized health intervention aiming to improve the limited aspects of local ANC program.

Keywords: Knowledge, Practice, Antenatal care, Prenatal care, Pregnant women.

\section{I. ĐĂT VẤN ĐỀ}

Thai nghén là một hiện tượng sinh lý bình 